\title{
Analysis of Process of Metal Filling of Ceramic Preforms Using Darcy's Law
}

\author{
K. Gawdzińska ${ }^{a, *}$, P. Szymański ${ }^{b}$ And D. NAGOlska ${ }^{b}$ \\ ${ }^{a}$ Department of Machines Construction and Materials, Maritime University of Szczecin, \\ Willowa 2-4, 71-650 Szczecin, Poland \\ ${ }^{b}$ Institute of Materials Technology, Poznań University of Technology, \\ pl. Piotrowo 3, 60-965 Poznań, Poland \\ Doi: 10.12693/APhysPolA.138.189 \\ *e-mail: k.gawdzinska@am.szczecin.pl
}

\begin{abstract}
The possibility of performing recycling process of metal-matrix composites was determined before, using only the Dupre equation. This equation allows to determine superficial conditions in the system: liquid metal (matrix)-solid reinforcement-medium, favouring the process of autogenous outflow of liquid matrix from the porous reinforcement. When using this method, the influence of the structure parameters of reinforcement preforms on examined process is difficult to assess. In order to do so, Darcy's law of flow must be used for analysis of liquid metal matrix outflow's process. Application of this law enables defining the influence of temperature and time of recycling process on matrix metal's yield.
\end{abstract}

topics: cast, metal-matrix composites, infiltration, Darcy's Law

\section{Introduction}

Cast metal composite materials manufactured by saturating the preform with liquid matrix metal can be made of: short fibers, pressed in the form of felt, porous structures, ordered fibers, etc. Mold filling can be achieved in a number of ways, including injection or suction methods $[1,2]$. The variety of reinforcing structures enables production of composites with good processing properties and favors their proper shaping [3-6]. However, it also causes problems during both the selection of the saturation conditions $[7,8]$ of reinforcement preforms and the recycling $[9,10]$ of composites obtained this way. Because many problems related with recycling of metal-matrix composites are not solved yet, the presented paper analyzes some of them.

\section{Selection of recycling process conditions}

Jackowski, Szweycer and the authors of $[11,12]$ formulated the condition for the automatic outflow of liquids from pores. According to Fig. 1, it was described based on the surface properties of the system, not taking into account the shape and dimensions of the pores. It has the form:

$$
p_{1} \neq p_{2},
$$

where $p$ is capillary pressure.

It is not important which of the values of the capillary pressure is greater, because their mutual relations only determine the direction of the outflow of matrix metal out of the reinforcement pores.
Experimental studies [13, 14] indicate, however, that the above condition is sufficient only in special cases in which the pore shapes are approximately regular. Arrangement: reinforcementwarp-medium, characterized by irregularly shaped pores is shown in Fig. 1.

The leaking of liquid metal from the pores of the reinforcement should be considered in three phases.
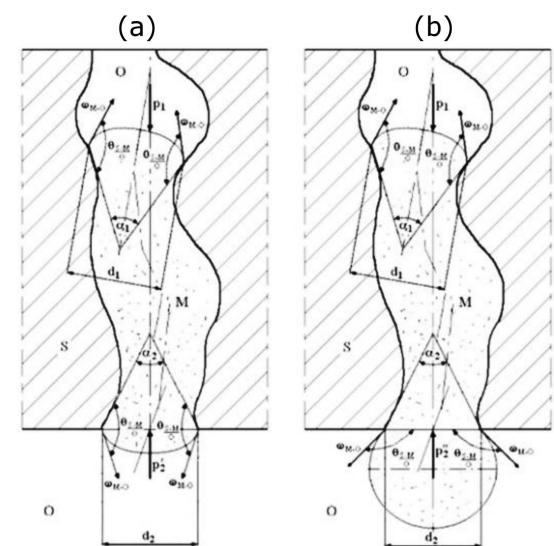

(c)

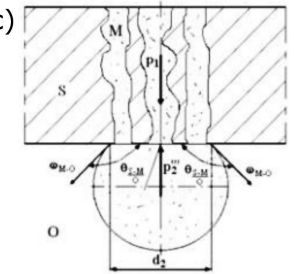

Fig. 1. Stages of liquid metal matrix outflow from pores of composite reinforcement [15]. 
The relocation of liquid metal matrix in reinforcement capillaries is the first stage of the process. The following equation describes the condition under which the process will be autogenous [9, 13]:

$$
\begin{gathered}
\omega_{\mathrm{M} \mid \mathrm{G}} \cos \left(\theta_{\frac{\mathrm{S}}{\mathrm{G}} \mid \mathrm{M}}\right)-\omega_{\mathrm{O} \mid \mathrm{G}} \cos \left(\theta_{\frac{\mathrm{S}}{\mathrm{G}} \mid \mathrm{O}}\right) \\
+\frac{d_{1}}{d_{2}} \omega_{\mathrm{M} \mid \mathrm{O}}<O,
\end{gathered}
$$

where subscript letters M, O, G denote liquid metal, liquid medium, and a gas, respectively, while $\mathrm{S}$ is a solid state. The surface energy $\omega$ in (2) is determined at the interfacial boundaries of the two media (given in the subscript). In turn, $\theta$ is the extreme wetting angle of the solid state material in gas atmosphere $\mathrm{S} / \mathrm{G}$, through the liquid metal matrix $\mathrm{M}$ and through liquid recycling medium $\mathrm{O}$.

In case of capillaries collection, which is the composite reinforcement preform, second stage takes place along with the third stage. It causes outflow of liquid matrix from pores of reinforcement and forming the drop of metal. The following condition must be fulfilled by the system to ensure the process being self-contained $[13,15]$ :

$$
\frac{d_{2}}{d_{1}} \frac{\cos \left(\theta_{\frac{\mathrm{S}}{\mathrm{O}} \mid \mathrm{M}}-\frac{\alpha_{1}}{2}\right)}{\sin \left(\theta_{\frac{\mathrm{S}}{\mathrm{O}} \mid \mathrm{M}}\right)}<-1
$$

In authors' opinion, (2) and (3) are divided regarding which stage will be decisive for the process course. From presented equations it can be determined that course of all stages of the liquid metal matrix outflow process from pores of reinforcement is highly dependent on superficial parameters of the system: reinforcement-metal of the matrix-medium, like wetting angle or surface energy. Performed analysis [13, 15] shows that selection of beneficial parameters of wetting is only one of many conditions allowing automatic course of the liquid metal matrix outflow process from porous reinforcement preform. Ongoing research has proven that, depending on the character of the reinforcement (shape and number of pores) with identical superficial properties of the recycling system, significant differences in yield of metal can be acquired.

Influence of the type of reinforcement preform can be considered in form of such parameters as: capillary angle of flare and diameters of capillaries $d_{1}$ and $d_{2}$. These parameters, when it comes to examining such complex and non-homogeneous structures as in reinforcement preforms, are impossible for unequivocal determination. Because of it, basing on presented (2) and (3), only a preliminary selection of recycling medium can be made. This choice will not guarantee high efficiency of the recycling process. Taking into consideration only above mentioned equations, basic parameters of the recycling process, like temperature and time cannot be determined. However, it has been decided to develop another law, allowing to determine more simply the influence of reinforcement preform structure on recycling process of examined materials.

\section{Application of Darcy's law for evaluation of structure of reinforcement preforms}

The process of outflow of liquid metal matrix from composite reinforcement preform is very similar to, widely occurring in nature, processes of flow, e.g. used in technology flows of gases and liquids through different kinds of filters. Reinforcement preforms, similarly to mentioned materials, are characterized with porous, permeable structure. They contain a huge number of pores (empty spaces) with various shape and small dimensions comparing to dimensions of whole preform. In order to describe the flow of liquid through such materials, Darcy's formula is used. This law is described by a phenomenological equation [16] that determines dependence between filtration velocity of liquid flowing through porous medium $(U)$ and occurring gradient of pressure grad $(P)$. Due to this law, velocity of filtration of liquid flowing in porous medium $(U)$ is directly proportional to the pressure drop on the unit of medium thickness $(\Delta P / L)$ and inversely proportional to viscosity of flowing liquid $(\mu)$. Coefficient of proportionality (permeability $K$ ) is a constant value, characteristic for given porous medium. In such porous medium, the velocity of filtration of liquid flowing $U[\mathrm{~m} / \mathrm{s}]$ can be written as

$$
U=-\frac{K}{\mu} \frac{\Delta P}{L} .
$$

Permeability $K\left[\mathrm{~m}^{2}\right]$ is dependent on filtration coefficient $k$ :

$$
K=k \frac{\mu}{\rho g},
$$

where $\mu$ stands for the absolute viscosity of measurement liquid $[\mathrm{Pa} \mathrm{s}], \rho$ stands for the density of measurement liquid $\left[\mathrm{kg} / \mathrm{m}^{3}\right], g$ stands for the acceleration of gravity $\left[\mathrm{m} / \mathrm{s}^{2}\right]$.

Filtration coefficient $k$ depends on total porosity of the medium and also on the size and shape of pores and its determination is relatively easy [17]. It can be done, for example, during analysis of water-permeability of porous medium with constant pressure method, while using a device with scheme presented in Fig. 2.

Performing measurements with this method, parameter measured is volume of water $V$ flowing through sample of thickness $L$ and of area of crosssection $A$ in time of $t$. The known parameters are height $\Delta h$ and area of cross-section $A=\Pi(\varphi / 2) 2$. Coefficient $k[\mathrm{~m} / \mathrm{s}]$ is determined by transforming (5) to the form

$$
k=\frac{V L}{A t \Delta h} \text {. }
$$

This method is mostly used for measurement of soil permeability [18] but can also be used when it comes to measure the permeability of reinforcement preforms and also other structure, e.g. foams, polymers, porous ceramic moulds [18-24]. Application of Darcy's law for analysis of recycling process of metal matrix composites with saturated 


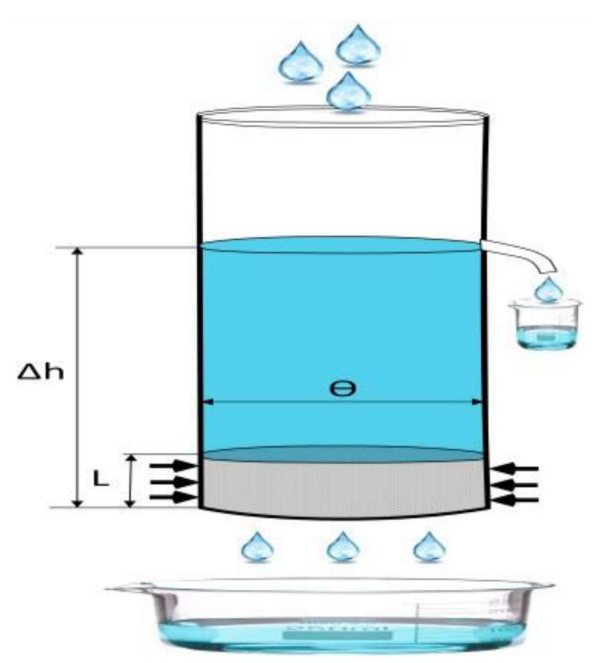

Fig. 2. Scheme of the station for water permeability measurement of reinforcement preforms.

reinforcement can allow to determine the influence of reinforcement character on the process of liquid matrix outflow from porous reinforcement preform by determining the coefficient of filtration $k$. Basing on the fact that viscosity of the matrix metal $\mu$ is dependent on temperature $T$, it can also allow to determine the influence of this parameter on the velocity of matrix metal outflow, giving necessary time of running the process as the outcome.

\section{Conclusions}

Efficiency of recycling process is highly dependent on reinforcement preform shape. Parameters of reinforcement structure, used in equations for capillary pressure determination are almost impossible for unequivocal determination. It is however possible to define the influence of reinforcement preforms structure on the process of liquid metal matrix outflow by determining the coefficient of filtration $k$ of the reinforcement material. A linear dependence exists between filtration velocity $U$ (determined basing on Darcy's law) and matrix metal yield. Thanks to this dependence, influence of recycling process temperature on matrix metal yield can be determined. It is also possible to estimate the time of process necessary to obtain specified yield.

\section{References}

[1] M. Nabiałek, B. Jeż, K. Błoch, P. Pietrusiewicz, J. Gondro, J. Magn. Magn. Mater. 477, 214 (2019).

[2] M. Nabiałek, B. Jeż, K. Błoch, J. Gondro, K. Jeż, A.V. Sandu, P. Pietrusiewicz, J. Alloys Compd. 820, 153420 (2020).

[3] K. Gawdzińska, K. Bryll, D. Nagolska, Arch. Metall. Mater. 61, 177 (2016).
[4] Recikling — informaciya k razmyshleniyu.

[5] D. Przestacki, R. Majchrowski, L. Marciniak-Podsadna, Appl. Surf. Sci. A 388, 420 (2015).

[6] K. Naplocha, K. Granat, Archiv. Metall. Mater. 59, 1125 (2014).

[7] J. Grabian Studia, Maritime Univ. Szczecin 35, 3 (2001) (in Polish).

[8] V. Michaud, A. Mortensen, Composites, Part A 32, 981 (2001).

[9] J. Jackowski, Arch. Foundry Eng. 9, 77 (2009).

[10] J. Jackowski, Arch. Mech. Techn. Automation 29, 29 (2009).

[11] D. Nagolska, Ph.D. Thesis, WBMiZ PP, Poznań 2002.

[12] D. Nagolska, M. Szweycer, Kompozyty (Composites) 2, 55 (2006) (in Polish).

[13] D. Nagolska, K. Gawdzinska, Def. Diff. Forum Online 326-328, 488 (2012).

[14] E.K. Aba, M.A. Badar, J. Technol. Studies 39, 42 (2013).

[15] J. Jackowski, D. Nagolska, M. Szweycer, P. Szymański, K. Gawdzińska, J. Grabian, Recykling metalowych odlewów kompozytowych, Polska metalurgia w latach 2002-2006, Metallurgy Committee of Polish Academy of Science, Cracow 2006 (in Polish).

[16] H. Darcy, Les Fontaines Publiques de la Ville de Dijon, Dalmont, Paris 1856 (in French).

[17] E. Myślińska, Laboratory Methods of Soil Investigations, Wydawnictwo Uniwersytetu Warszawskiego, Warsaw 2006.

[18] Z. Pazdro, B. Kozerski, General Hydrogeology, Wydawnictwa Geologiczne, Warsaw (1990).

[19] P. Popielarski, Z. Ignaszak, Adv. Structur. Mater. 63, 181 (2016).

[20] D. Czarnecka-Komorowska, T. Sterzynski, M. Dutkiewicz, Int. Polym. Process. 31, 598 (2016).

[21] M. Kozak, R. Gordon, A. Bejger, Sci. J. Maritime Univ. Szczecin 45/117, 17 (2016).

[22] M. Ratajczak, M. Ptak, L. Chybowski, K. Gawdzińska, R. Będziński, Materials 12, 271 (2019).

[23] W. Slaczka, K. Bryll, E. Piesowicz, K. Pilip, J. Orymowska, K. Błoch, Acta Phys. Pol. A 135, 246 (2019).

[24] A. Bejger, K. Gawdzinska, Metalurgija 54, 361 (2015). 